\title{
Evolution of Transformation Approaches of the Consumption During Public Relations Informatization
}

\author{
Julia Nanakina ${ }^{1}{ }^{*}$ Alexey Mikhailov ${ }^{1}$, Olga Ryabova $^{1}$ \\ ${ }^{1}$ Branch of Ivanovo State University*, Russia \\ "Email: artamon3@yandex.ru
}

\begin{abstract}
The conditions of the modern economy often dictate the inherent use of digital technologies based on the management of information on different scales, quality, structure and nature in the field of consumer processes. Modern information can become a measure of measurement, boundaries, expanding and cutting consumption volumes, which determines qualitatively new formats of objects and subjects of this sphere. Reproduction processes in the economy today are based not on the rule of "limited resources", but on the new paradigm of "information overabundance", on which it is necessary to build effective consumer practices. This trend creates a demand for information technology, and they, in turn, transform the sphere of consumption. This article aims to develop the theory of consumption based on the systematization of modern trends in the transformation of the role and place of consumer processes at each stage of the evolutionary development of social relations, as well as to classify the main research approaches and identify signs of the consumption sphere to form an image of a new consumption model in the context of global informatization. This research is based on the interaction of the fundamental theory of consumption and the theory of the development of the information economy using subject-object, structural-functional, historical and logical research methods, as well as methods of abstraction, systematization and classification.
\end{abstract}

Keywords: Consumer trends, Consumer qualification, Consumption model, Consumer barrier, Qualitatively new consumer, Synergistic effect of consumption, Informatization of public relations.

\section{INTRODUCTION}

If until now, the digital space was formed locally or point-wise, today global digitalization strategies prevail. In this regard, today among the key factors for the success of consumer activities can be called: information competence in the field of consumption and increasing the level of knowledge in the field of working with information in consumption [1].

The combination of the production and product approach with information technology allows you to manage the consumption sector effectively.

As part of the national project "Digital Economy", the Government of the Russian Federation plans to launch epassports, a unified cloud infrastructure ("Digital Profile"), connect $97 \%$ of the population to the Internet, launch 5G networks, and increase the cost of universal digitalization by 3 times. At the same time, the demand for information resources, technologies, systems is growing rapidly and does not coincide with the growth of consumer qualifications and culture of the population.
For the period 2010-2017, the share of households with access to the Internet increased 1.6 times - up to $76.3 \%$. The gap in Internet access for urban and rural residents is decreasing: in 2013 it was 1.5 times (72.8 and $49.5 \%$ of households, respectively), in 2017 - 1.2 times (79.5 and $66.5 \%$ ). The share of the most active (daily) Internet users over the past 8 years has grown by 2.3 times, reaching $60.6 \%$ in 2017 [2]. Trends can trace the influence of digital resources as the main factor in the development of information consumption:

- transformation of goods and services of mass consumption ("smart", knowledge-intensive informationally complex goods);

- changing the role and value attitudes of consumption in general (symbolism);

- expanding the scale of influence on the consumer of IT-technologies (e-commerce, on-line payment, spam advertising);

- the formation of new patterns of consumption due to multichannel, availability of information; 
- the growth of new forms and types of employment (self-employment), and as a result - the growth of additional income and overall labour productivity;

- changing the time boundaries of the organization of consumption (structure of working and free time);

- activation of the use of electronic, network and communication channels of communication in the organization of consumption, etc.

In the system of economic relations, there is a complete transformation of the role, functions, structure and content of consumption as a phase of the reproductive process.

The restructuring of the consumption sphere is due to historically objective processes and conditions for the development of digital technologies, which is expressed by the change in goods and services, the formation of new consumption patterns, income differentiation and diversification of demand, as well as the development of a new innovative and informational strategy of socioeconomic relations of all economic entities.

The problem of interaction between the information economy and the sphere of consumption can be studied from the angle of the following evolutionarily formed and scientifically based approaches:

- reproductive;

- information-innovative;

-nanoeconomic (internal restructuring of consumption of all household members).

\section{REPRODUCTIVE APPROACH}

Production and consumption are asymmetric: at different stages of economic development, there is a disproportion characterized by the dominance of one of production or consumption functions [3].

We remember that in an industrial economy, consumer processes are assigned the role of subordination to production. M. Porter argues that production is a process of consistent creation and accumulation of value, a "value chain" [4]. A. Marshall and his followers consider consumption as negative production since, in the process of consumption, there is a decrease or destruction of utility [5].

In the non-classical theory, there is a change in the functions of production and consumption. In the works of $\mathrm{G}$. Becker, consumption is a production of a particular kind: in the process of consumption, essential consumer goods are produced, which are directly included in the target function of the consumer [6]. The consumer, using goods and services, in the process of consumption, extracts useful effects from them and thereby satisfies his needs, stimulating their new round.
Note that already in a postindustrial economy, information becomes the central element of production. D. Tapscott believes that one of the hallmarks of the new digital-digital society is the transformation of the manufacturer-consumer relationship, where the boundaries between production and consumption are erased, mass production is replaced by mass production individualized [7]. The consumer begins to manage production, that is, to stimulate producers to produce goods that meet his interests, requirements, rules, principles, etc. And the market is acquiring a "consumer colour", where information technologies create conditions for the intensification of consumption.

The new network-type economy activates consumers involving their knowledge, experience, capabilities in production processes, new technological developments. At the same time, the consumer is recognized as a part of the entire production machine, an active corporate resource. And the consumer begins to play a dominant role in the reproduction process. Economic socialization and stratification are moving into the space of consumption (sociality) [8].

\section{INFORMATION-INNOVATIVE APPROACH}

Researchers F. Mahlup, M. Porat, Y. Masuda, note the versatility and radical transformations that the information revolution has brought to all spheres of public life $[9,10,11]$. In the information society, according to W. Martin, living standards, forms of organization of work and leisure activities, the education system and the sphere of consumption are influenced by the progress of information and knowledge [12].

The development of information technologies determines new lifestyles, values, benchmarks, consumer strategies (that is, their transformation):

1. Simplification of the processes of rationalization of consumption, as a result of which there is a saving of time, an increase in the usefulness of goods (which creates new requirements for the service sector and the level of service).

2. Acceleration of the implementation of consumer processes through the adoption of rational decisions (calculated, deliberate, built on the scientific approaches of the organization).

3. Strengthening creative functions as information becomes available, the consumer does not just perform consumer functions, he creates new products (information, intellectual, home-made and family business products that increase his income).

4. Generation of new sectors of the economy (tertiary and quaternary sectors).

5. A change in the content side of consumption forms a new character of consumer behaviour, shifting towards consumption more images than useful properties of 
goods. Symbolic consumption is becoming a growing trend in the 21 st century. As A. Dolgin notes, "objects are increasingly used not just as things with useful properties, but as signs, symbols, cultural codes - in a word, as signals and messages" [13].

6. Transformation of the qualitative characteristics of consumer activities of households (individualization of consumption is ensured through new forms of consumption on-line format, robot consumption, the introduction of virtual cash registers and stores), which creates the image of a new consumer with special intellectual abilities. The rate of obsolescence of consumer products increases and, generally, does not equal the rate of physical wear and tear. Indicators of the classical value of a product, as a key consumption property, switch to indicators of science intensity, multifunctionality, stylization and status. In this case, the information asymmetry between the participants in the consumption processes increases. Zhuravleva G.P. notes that the wealth "...becomes non-commodity" [14].

As a result of systematization of new trends in the development of the sphere of consumption, the authors carried out a criterion cut of the main characteristics of new consumption to the industrial and information economy (table 1):

The data analysis showed that the sphere of consumption had undergone several changes in the development of social relations as a result of the transition to an information-type economy. The growth of innovations and scientific and technological progress in the field of production is fully reflected in these trends in consumption. Information and innovation characteristics of consumers are becoming a significant category in the context of the transformation of socioeconomic relations, built at a qualitatively new level.

Some researchers (P. Saviotti, A. Puka) argue that the role of the consumer as an innovator has been underestimated in terms of focus on production, innovation and economic growth [16]. At the same time, it should be understood that production innovations regarding the release of goods and services will be negligible if they do not find satisfaction from potential consumers. A diminishing marginal utility and an increase in consumer costs in the future will form a trend - the lack of a variety of consumer baskets if information technology does not intervene in these processes.

As a result of evolution, it is consumer trends that determine the socio-economic, technological, innovative and communication capabilities of manufacturers, which generates economic growth, both for enterprises and industries. However, when the information and innovation component of consumer processes is outpacing, consumer qualifications are losing their quality level and need to be improved (layering new consumer knowledge). And the higher the rate of these changes, the faster a certain consumer barrier forms (for assessing the consumer properties of goods). And the rational consumer orientation that grows with experience becomes limited, which requires a new reassessment of consumer practices and training. Therefore, the learning process should be built into the consumption process in such a way that these categories are connected in the form of an "educational-consumer puzzle" with sifting and assimilation of the necessary information. Thus, the formation of an integral new property of the product informatization - is observed.

The result of consumption in an informationinnovative society is a qualitatively new consumer, which becomes the basis for the development of the human potential of society as a whole, which ensures the quality and level of economic growth, and the sphere of consumption becomes the starting point of the production process and its qualitatively new content.

V.L. Inozemtsev writes that under the conditions of the information economy, the theoretical postulates of classical science become limited, which requires a

Table 1. Systematization of consumption characteristics in the industrial and information economy [15]

\begin{tabular}{|c|c|c|}
\hline Consumption criterion & Industrial economy & Information economy \\
\hline Value, place & Subordination regarding production & Exceed over production \\
\hline Trend & Standardization, samples, scale & Non-standard, individuality, locality \\
\hline Structure of needs & The predominance of material forms & $\begin{array}{l}\begin{array}{l}\text { Prevalence of intangible forms } \\
\text { (information, knowledge) }\end{array} \\
\end{array}$ \\
\hline Style and character, scale & Pattern, volume, certainty & Situational, minimal, symbolic \\
\hline Subjects and objects & $\begin{array}{l}\text { Products with a set of useful properties } \\
\text { and functions }\end{array}$ & $\begin{array}{l}\text { Images and symbols of products and } \\
\text { services }\end{array}$ \\
\hline Types & Classic, Standard, Mass, Traditional & $\begin{array}{l}\text { Status, symbolic, situational, role- } \\
\text { playing, virtual, trendy }\end{array}$ \\
\hline Value and usefulness & Decreasing, functional & Unspent, recycled \\
\hline Cost, expenses & Classic costs calculation & $\begin{array}{l}\text { Dominance in the calculation of } \\
\text { transaction costs }\end{array}$ \\
\hline Life cycle & Physical depreciation & Moral depreciation \\
\hline Quality control & By physical indicators & Accounting for "cloud" indicators \\
\hline Factors & Economic, non-economic & $\begin{array}{l}\text { Leading, innovative, informational, } \\
\text { organizational and managerial, moral }\end{array}$ \\
\hline
\end{tabular}


revision of the concept of investment activity [17]. Therefore, when information becomes an exceptional resource of consumption, it can be considered a significant investment. At the same time, consumers, as carriers of entirely new patterns of behaviour, will form a new model of the "consumer economy".

\section{NANOECONOMIC APPROACH}

Within this approach, a system of indicators of a new model of consumer activity within households will be designated, which reflects the consumer trends of the information society. Among the main indicators of this qualitatively new model may be:

A) the level of formation and development of qualitatively new information-type needs (personalized training in the sphere of consumption, for example, webinars, online consultations, necessary for residents of remote and small cities);

B) indicators of the rational organization of consumer activity for a large mass of households, where basic needs will be met quickly, efficiently, with no particular moral, material costs, which will free up time for selfimprovement, training, additional income due to digitalization;

C) the ratio of the elements of the system of costs with obtaining a long-term synergistic effect of consumption (the total result from the combination of all elements of the system of consumption), while the expenditure part may not always matter (the long-term effect is estimated higher than the costs of obtaining it);

D) indicators of consumer interaction with the entire infrastructure and subjects of consumption (blurring the boundaries between production, sales, consumption, household, government, etc.);

E) the possibility of using public funds, forms, methods, tools capable of developing their consumer sphere through new sources of income, contacts, ties with the main state institutions in the sphere of consumption;

F) indicators of changes in the system of values, culture, principles of consumer practices in the new conditions of informatization, which follow in the context of a complete transformation of consumer behaviour and society as a whole (emphasis on environmental friendliness, locality, individuality, healthy image, loyalty, innovation, etc.).

\section{CONCLUSION}

Consumer activity is not only the basis of all human life activity but also the basis of his self-development. Therefore, the consumption must be given special attention both from the point of view of implementation practice (the study of consumer behaviour patterns) and from the point of view of science theoretical research.
Previously, we carried out several studies aimed at identifying the features of the theory and practice of implementing consumer activities in various socioeconomic, administrative and geographical conditions using the example of small towns, cities of the Far North, etc. [18], which has already formed several substantiated theoretical positions in several trends, criteria and factors. However, it should be noted that these studies need to update the evidence base.

In this study, we have formed several scientific provisions expanding economic knowledge in the field of consumption. Analysis of the consumption sphere from the standpoint of reproductive, information-innovative and nanoeconomic approaches allows us to conclude that the meaningful role of consumption has grown significantly in economic science, as part of the expansion of its categorical apparatus, the introduction of new potentially important economic elements, models adapted to the new conditions of social relationships.

Thus, the systematization and grouping of qualitatively new approaches to the study of consumption made it possible to conclude the following:

1. Based on the generalization of the points of view of several authors of foreign and domestic economic science, the main approaches to consumption as a qualitatively new category of interdisciplinary nature are formulated, the place and role of consumption in the reproduction process are substantiated, the ratio of the sphere of consumption in macro-, micro- and nanoeconomic terms is determined, which allows for a systematic assessment of interchangeable and complementary benchmarks of consumer processes based on the evolution of approaches.

2. Consumption as an interdisciplinary category allows us to show that the knowledge of economic theory in the field of consumption must be enriched by integrating the knowledge of other sciences, the object of which is consumption. Social, economic, historical, psychological, cultural, informational components of the consumer sphere determine the need to combine these areas into a single system of knowledge, which would make it possible to form the image of a qualified consumer of a new level, capable of maintaining competitive positions in the markets of the modern information society.

3. In several economic disciplines, it is necessary to single out separate sections (sub-disciplines) that will systematize knowledge in the field of consumption (in economic theory - nanoeconomics, in marketing consumer behaviour, in economic psychology and sociology - socio-psychological consumer behaviour, in cultural and historical disciplines - culture and history of consumption, etc.). This will gradually expand this area of knowledge through theoretical and applied research. 
4. As a result of the integration approach, a theoretical system of "consumption" indicators has been developed based on reproductive, information-innovative and nanoeconomic approaches, which includes several vital indicators as a result of the information transformation of society in general and consumption in particular.

5. Transformation of consumption as a process of systemic changes is characterized by changes in subjects, objects, objects, structural elements, principles, types, forms, instruments, trends in consumption.

\section{REFERENCES}

[1] Digital transformation in Russia, Review and recipes for success, Analytical report based on a survey of representatives of Russian companies, 2020. Access mode: https://komandaa.pro/projects/dtr 2020 (application date 23.11.2020)

[2] What is the digital economy? Trends, competencies, measurement [Text]: reports to XX Apr. int. scientific conf. on the problems of economic and social development, Moscow, April 9-12, 2019/G.I. Abdrakhmanova, K.O. Vishnevsky, L.M. Gokhberg and others; scientific ed. L.M. Gokhberg; NRU Higher School of Economics, M.: Higher School of Economics Press, 2019. p. 7.

[3] I. Strelets, Innovative economy, M, 2012, p. 105

[4] M. Porter, Competition, Translation from English M.: Williams, 2005, p. 109.

[5] A. Marshall, Principles of Economic Science: In 3 volumes/Translation from English, M. Vol. 1. (1993) 153.

[6] G. Becker, Family Economics and Macrobehavior//USA, Canada: Economics, Politics, Ideology 2-3 (1994) 99-107.

[7] D. Tapscott, Electronic digital society, Kyiv, 1999, p. 76.

[8] A.V. Ovrutsky, The social philosophy of consumption: theoretical and methodological aspects, Rostov-on-Don, 2010, pp. 137-138.

[9] F. Mahlup, Production and spread of knowledge in the United States, M.: Science, 1966.

[10] M. Porat, M. Rubin, The Information Society: Development and Measurement, Wash., 1978: Stonier T. Wealth of Information L., 1983

[11] Y. Masuda, The Information Society as Postindustrial Society, Bethesda $\mathrm{MD}^{\wedge}$ World futures Society, 1981.

[12] W.J. Martin, The Global Information Society, Aldershot: Aslib Gower, 1997, p. 3.
[13] A.B. Dolgin, New Economy Manifesto, The second invisible hand of the market, M., 2010.

[14] G.P. Zhuravleva, The contours of the neoeconomics theory and modification of its basic categories//Bulletin of the REA 2 (2009) 20.

[15] P.P. Saviotti, Technological evolution, variety and the economy/P.P. Saviotti, - Cheltenham: Edward Elgar, 1996; Saviotti P.P., Pyka A. Economic development by the creation of new sectors, Journal of Evolutionary Economics, Vol. 14, 2004.

[16] V.L. Inozemtsev, Modern post-industrial society: nature, contradictions, prospects, M.: Logos, 2000, p. 6.

[17] Yu.S. Nanakina, The system of conceptual approaches to the study of consumer activity of households in the framework of economic theory//Fundamental research. 3 (2017) 180-184. 